\title{
LA COMUNICACIÓN COMO HERRAMIENTA CLAVE DEL COMMUNITY MANAGER. JUSTIFICACIÓN DE SU PRESENCIA EN LAS FACULTADES DE COMUNICACIÓN
}

Rocío Alcántara-López: Universidad de Sevilla. España rocio.alcantara.lopez@gmail.com

\section{RESUMEN}

Desde que fuese acuñado por Dale Dougherty de O’Reilly Media en 2004 en una conferencia sobre el Universo de la Web 2.0, el término ha cambiado de forma vertiginosa. En esta vorágine nació, hace apenas un lustro, una figura que nunca antes había generado tanta controversia en cuanto a sus responsabilidades y encaje organizativo: el Community Manager. La demanda de información sobre este nuevo perfil crece a un ritmo vertiginoso, algo normal si se tiene en cuenta que estamos ante una actividad para la que, por el momento, no es necesaria titulación alguna o conocimientos técnicos específicos. Esto ha propiciado que sean muchas las voces que se hayan apresurado a catalogarla como una filosofía de vida más que como una sólida salida laboral. Se equivocan. Ser Community Manager no consiste únicamente en manejar con destreza las Redes Sociales a favor de una empresa determinada que busca aumentar su repercusión social, sino que ha de poseer conocimientos sobre Estrategias de Comunicación en línea para llegar a la comunidad de manera efectiva. Esto unido a que el perfil del periodista/comunicador está cada vez más vinculado con la tecnología hace más que necesaria su consideración como especialización dentro del ámbito periodístico.

PALABRAS CLAVE: Community Manager - Web 2.0 - Comunicación - Empresa Marketing

\footnotetext{
${ }^{1}$ Autor correspondiente

Rocío Alcántara-López: Doctoranda. Universidad de Sevilla. Sevilla (España).

Correo: rocio.alcantara.lopez@gmail.com
} 


\title{
COMMUNICATION AS A MAIN KEY FOR THE COMMUNITY MANAGER. JUSTIFICATION FOR ITS PRESENCE IN SCHOOLS OF COMMUNICATION
}

\begin{abstract}
Since it was coined by Dale Dougherty of O'Reilly Media in 2004 at a conference on the universe of Web 2.0, the term has changed dramatically. In this maelstrom was born just five years ago, a figure that had never generated as much controversy as to their responsibilities and organizational fit: the Community Manager. The demand for information on this new profile is growing at a rapid pace, which is normal if you consider that this is an activity that, for the moment, there is no need any qualifications or expertise. This has meant that there be many voices have been quick to classify it as a philosophy of life rather than a solid job prospects. They are wrong. Being a community manager is not only skillfully managing social networks for a given company looking to increase their social impact, but must have knowledge of online communication strategies for reaching the community effectively. This coupled with the profile of the journalist / communicator is increasingly linked with the technology that makes it necessary for consideration as a specialization within the field of journalism.
\end{abstract}

KEY WORDS: Community Manager - Web 2.0 - communication - business marketing

\section{INTRODUCCIÓN}

En pleno siglo XXI nadie duda de que Internet ha llegado para quedarse. Gracias a su existencia, podemos incluso decir que han desaparecido las fronteras en nuestro Planeta. ¿Quién no ha entablado en alguna ocasión una conversación con alguien a miles de kilómetros de distancia y a quien ni siquiera conoce? ¿Quién no ha probado a comprar algo a través de Internet? ¿Cuántos de los que ahora leéis estas páginas no ha buscado las últimas novedades tecnológicas del mercado? Hoy todo es mucho más sencillo. Y es que hablar de Internet y de las Redes Sociales en los tiempos que corren es hacerlo de una auténtica revolución, no sólo tecnológica sino social. 
Al margen de cuestiones tan simples como adquirir las nuevas tendencias en moda, hacer la compra del mes e, incluso, encontrar pareja, Internet nos ofrece un amplio abanico de posibilidades que se encuentran encaminadas no sólo a mejorar nuestro tiempo de ocio y disfrute, sino a potenciar la economía que nos rodea, y que tanto se resiente en estos instantes. En los últimos tiempos, Internet ha logrado alzarse como la herramienta más eficaz para todo tipo de organizaciones que deseen afianzar su posicionamiento en el mercado alcanzando numerosas ventajas competitivas con las que alzarse victoriosos ante sus 'enemigos' del mercado.

Íntimamente relacionados con esta nueva situación aparecen profesionales hasta el momento insospechados. De todos ellos, en el presente artículo vamos a centrar nuestra atención en el Community Manager. Un perfil profesional completamente novedoso que, como todo lo recién llegado, no está exento de polémica. Sus habilidades y conocimientos aún hoy se encuentran en terreno pantanoso y sólo el tiempo se encargará de dar forma a un puesto de trabajo que emerge en un mercado laboral que se presenta ante nosotros, cuanto menos, inestable.

El hecho de que la base de su día a día sean las habilidades comunicativas es justificación más que suficiente, a nuestro entender, para que sea desde las Facultades de Comunicación desde donde se dirija su formación académica. Algo para lo que tendrían que incluir en sus planes de estudio materias específicas que impidan que las empresas acaben contratando a 'impostores' que, sin conocimientos reales pero por haber realizado un desembolso económico desorbitado, se definan en sus currículos como Community Managers perfectamente preparados.

\section{DESARROLLO}

\subsection{Internet: la gran plataforma de la comunicación del siglo XXI}

Mucho ha llovido desde que ARPANET hiciera su aparición en plena Guerra Fría allá por la década de los 60- convirtiéndose en una red exclusivamente militar nacida con el objetivo de que en el hipotético caso de que se produjese un ataque ruso, los Estados Unidos pudieran acceder a la información militar desde cualquier punto del país.

Hoy, esta sencilla Red - constituida únicamente por cuatro ordenadores en sus orígenes- ha crecido vertiginosamente hasta llegar a ser lo que en el siglo XXI se ha dado en llamar Red de Redes. A lo largo de todas las décadas transcurridas, lo que en un primer momento se trataba de un grupo de páginas casi estáticas donde la gente/usuarios tenían la oportunidad de observar contenidos predeterminados (Web 1.0), hoy se alza como un espacio empleado no sólo para obtener todo tipo de datos, sino para enviarlos, modificarlos e incluso hacer operaciones económicas con ellos desde cualquier rincón del Planeta en el que nos encontremos. 
La Web 2.0 -denominación que sustituyó a la primigenia Web 1.0- es, por lo tanto, un escenario en el que todo individuo que se acerca se comunica y relaciona estableciendo interacciones en un entorno virtual o ciberespacio, a diferencia de las interacciones que tienen lugar en el día a día, en un contexto físico y social inmediato (Cornwell y Lundgren, 2001, pp. 197-211). Para Celaya,

Una web mucho más colaborativa que permite a los usuarios acceder y participar en la creación de los contenidos y el conocimiento y en la distribución de los miembros entre los integrantes de las redes sociales a las que pertenecen como consecuencia de esta iniciativa entre tecnología, contenidos y personas, se generan nuevas oportunidades de negocio para las empresas. (Celaya, 2008).

$\mathrm{Y}$ es que "Internet ha pasado de ser un medio de comunicación bajo el modelo emisor-canalreceptor, y emula más al modelo circular de la conversación interpersonal, donde la retroalimentación es constante" (Hernández, 2007).

Por lo tanto, a tenor de lo expuesto por Hernández, la interacción de los usuarios es, a todas luces fundamental. Que todos tengamos la oportunidad de participar en los contenidos ofrecidos por la Red nos hace sentirnos parte de la misma otorgándole un valor adicional. Los usuarios de la Web ya no estamos sólo para buscar y recibir información, sino para emitirla, construirla y madurarla. En este sentido, Maqueira y Bruque apuntan que Internet ha logrado configurarse como "un entorno cada vez más colaborativo e interactivo, en una plataforma que permite la participación de los usuarios, la unión flexible y los rápidos flujos de información en redes sociales" (Maqueira \& Bruque, 2009, p.15)

Estamos, por lo tanto,

Ante nuevos escenarios en los que los internautas están cada vez más informados, saben mejor lo que quieren, son productores de contenidos colaborativos y, al mismo tiempo, consumidores (...) y se organizan en redes sociales catalizadas por las TICs. (Tapscot \& William, 2007).

\subsection{Las Redes Sociales en la comunicación organizacional. Su importancia en la interacción social}

La paulatina consolidación de Internet como herramienta base de comunicación social ha llevado a las empresas a ver en la Red un elemento clave a la hora de proceder a la modificación de la gestión que de su comunicación llevaban a cabo hace sólo unas décadas. El creciente desarrollo de las nuevas tecnologías y la comunicación digital que de los mismos ha emergido, dan forma a una realidad que no ha de pasar inadvertida para aquellas organizaciones que deseen renovar y Potenciar sus estrategias comunicativas de cara a la aparición de nuevos consumidores, ahora más inteligentes $\mathrm{v}$ meior interconectados. 
Con la llegada de Internet, fueron muchas las voces que pronosticaron un paulatino aislamiento entre las personas. Idea que, en pleno siglo XXI, ha quedado totalmente desechada. En este contexto, y para reforzar la potencialidad que presenta la Red a la hora de buscar lazos sociales basados en intereses comunes, apareció hace poco más de una década el fenómeno de las Redes Sociales On-line, una realidad que Navarro define como "el entresijo formado por las relaciones sociales que, desde los diferentes ámbitos de vida, y con diferente grado de significatividad, vinculan a un sujeto con otros". (Navarro, 2004); es decir, tal y como señala Castelló de manera sencilla "podemos decir que una red social es un grupo de personas que tienen algo en común y es por ese algo por lo que se conocen y se agrupan para interactuar y estar en contacto". (Castelló Martínez, 2010, p. $65)$.

Una definición sobre la que incide Castells al definir a las comunidades virtuales (también llamadas Redes Sociales Online) como "redes electrónicas autodefinidas de comunicación interactiva, organizadas en torno a un interés o propósito compartido, aunque a veces la comunicación se convierte en sí misma en la meta". (Castells, 2001, p. 395). Una comunicación que, si bien en la mayoría de los casos afianza los lazos de unión con aquéllos que conocemos, en otras ocasiones no viene sino a abrirnos las puertas hacia mundos desconocidos representados por usuarios de los que es posible ni siquiera conozcamos el rostro.

Lo que sí es cierto es que, al margen de ser un eficaz vehículo de comunicación entre los usuarios de la Red con independencia de su localización -y de su conocimiento mutuo-, "las redes sociales online representan un recurso al que cada vez con más frecuencia acuden los anunciantes a la hora de elaborar sus estrategias con el fin de alcanzar sus objetivos publicitarios". (Castelló Martínez, 2010, p. 14).

Unos objetivos que no tienen que ir únicamente encaminados a vender un producto o un servicio -que también- sino que, en la mayoría de los casos se sustentan en un reforzamiento de la imagen que de la identidad se proyecta en el conjunto de la Sociedad. Y es que, como diría Alloza, hoy en día, las empresas que forman parte del parque de negocios que nos envuelve han de convivir, teniendo en ocasiones incluso que sobrevivir, en un "entorno que comporta riesgos, pero también grandes oportunidades para aquellas organizaciones que están atentas a los cambios y reaccionan en la dirección adecuada y a tiempo". (Alloza, 2006, pp. 81-84).

En este sentido, tal y como afirman Christakis y Fowler como individuos "somos conscientes del efecto directo que ejercemos en nuestros enemigos y en nuestra familia" (Christakis \& Fowler, 2010, p. 43-44), no hemos de pasar por alto el impacto que una empresa $u$ organización puede poseer en el grueso de la población. Este hecho, del que cualquier entidad es plenamente consciente, ha propiciado que, en el último lustro, las Redes Sociales hayan sido entendidas por los dirigentes empresariales como la más eficaz de las herramientas para potenciar sus ventajas competitivas en el nicho de mercado en el que operan. Así pues, v parafraseando a la 
profesora De Salas, si Internet y las Redes Sociales permiten que empresas y usuarios puedan compartir la diversidad del escenario en el que ambos grupos se mueven, las primeras han de acercarse a los segundos planteando estrategias de comunicación online adecuadas a sus perfiles, de manera no intrusiva y respetando. (De Salas Nestares, 2010, p. 8).

Para las empresas, la gestión de su reputación en Internet se está convirtiendo en una de sus mayores preocupaciones. La interconectividad que se da en las Redes Sociales entre los usuarios origina que estos expresen públicamente sus opiniones y experiencias como consumidores. No obstante, las empresas no han de construir su imagen de cara al exterior basándose únicamente en las opiniones de aquéllos que alguna vez han utilizado sus servicios, sino que han de trabajar concienzudamente para lograr por ellos mismos afianzar su identidad y cultura corporativas, conceptos que van a convertirse en "los valores estratégicos que van a marcar la diferencia en la gestión de la organización, a lograr la satisfacción de las expectativas creadas en sus públicos y a acondicionar la imagen de la empresa en su entorno". (Castelló Martínez, 2010, p. 27).

\subsection{El Community Manager como responsable de la nueva comunicación empresarial}

Para que una corporación afiance su Identidad Visual -proceso en cuya consecución, y según Villafañe, el objetivo central ha de ser proyectar una imagen intencional de la organización, identificada con su posicionamiento estratégico (Villafañe, 1999, pp. 7779)- ésta tiene que ser consciente de que el primer paso para lograrlo radica en una estrategia comunicativa convenientemente estructurada y consolidada. Estrategias comunicativas que, con la llegada de Internet -en general- y de las Redes Sociales -en particular- han de fundamentarse en aspectos totalmente novedosos. Nuevas estrategias que no han venido sino a potenciar un nuevo tipo de comunicación que algunos han denominado 'comunicación digital' y de la que el Community Manager parece poseer todas las claves.

Pero, ¿qué es un Community Manager? ¿Qué habilidades ha de tener? ¿Con qué formación ha de contar? Es la gran revelación del mundo profesional de nuestros días pero verdaderamente nadie sabe bien la razón. Pocas veces un puesto de trabajo ha originado tanta controversia en torno a su formación, su salario, horas de trabajo, categoría profesional, etc. Lo que sí es cierto es que si introducimos el término en Google, España es el primer país en demandar información sobre este nuevo perfil, que ha visto incrementada su repercusión gracias al afianzamiento de las Redes Sociales. España es, además,

Uno de los pocos países donde este fenómeno ha adquirido el comportamiento de las llamadas burbujas: rápida popularización, establecimiento de una lucrativa industria en torno al mismo (asociaciones, academias, agencias, consultoras, etc. debate sobre su validez y, es de esperar, posterior pinchazo y desaparición. (Méndez \& Segovia, 2011). 
En la actualidad muchas empresas buscan un Community Manager. Y quizás, auspiciados por la crisis económica y el desempleo, son muchos los que se suben a este carro sin saber muy bien a qué van a tener que enfrentarse, calificando como'autodidacta' su proceso de formación.

Su auge en nuestros días es tal que en el año 2008 nació la Asociación Española de Responsables de Comunidades Online (AERCO), que define al Community Manager en los siguientes términos:

Es aquella persona encargada o responsable de sostener, acrecentar y, en cierta forma, defender las relaciones de la empresa con sus clientes en el ámbito digital, gracias al conocimiento de las necesidades y los planteamientos estratégicos de la organización y los intereses de los clientes. Una persona que conoce los objetivos y actuar en consecuencia para conseguirlos.

Por otro lado, David Coghlan, profesor en Trinity Collage de Dublin, define esta nueva profesión ligada a la Red como:

El arte de la gestión eficiente de la comunicación de otros online en las diferentes herramientas idóneas para el tipo de conversación que creamos conveniente con nuestros potenciales clientes (ya sea un blog, una comunidad a medida, una cuenta en Twitter, una Página de Fans en Facebook...). Es el rostro de la marca (Falla Aroche, 2010).

En conclusión, un Community Manager es una persona con amplios conocimientos sobre estrategias de comunicación en línea para llegar a la comunidad de manera efectiva. Es decir, un Community Manager, en contra de lo que hasta el momento algunas voces creen, no puede ser, o al menos no debe ser, una persona que únicamente posea amplias capacidades para estar conectado todo el tiempo a las Redes Sociales, sino que ha de ser un profesional al que deben requerírsele aptitudes muy específicas para desarrollar sus quehaceres de la manera más óptima y beneficiosa posible para el devenir de la empresa o institución para la que trabaje.

En este sentido, si bien hoy son numerosas las Academias y Centros que ofrecen lo que ellos llamar 'formación específica' para llegar a trabajar como Community Manager (en la mayoría de los casos pagando precios realmente desorbitados), son las Facultades de Comunicación las que deberían apostar por introducir en sus planes de estudios asignaturas que permitan a los alumnos lograr una especialización plena y clara en estas lides, sobre todo en unos momentos en los que al Periodista se le exige un amplio manejo en todo lo relacionado con las nuevas tecnologías. 
Gestión de contenidos y herramientas sociales. Dos pilares que sustentan el día a día de todo Community Manager. Dos pilares que se ensamblan mediante una estrategia de comunicación perfectamente dibujada, que el Comunicador o Periodista ha de moldear atendiendo no sólo a las necesidades de la empresa en cuestión, sino a las demandas que puedan surgir en el seno de la Sociedad.

\subsection{La comunicación, base de su día a día}

Un buen Community Manager, por lo tanto, ha de contar con conocimientos propios del mundo de la comunicación y, más concretamente, de la comunicación digital a la que hacíamos alusión con anterioridad en este documento, es decir, conocimientos relativos al uso de las tecnologías digitales con las que podrá agilizar en buena medida su trabajo como comunicador, así como destreza a la hora de romper con la comunicación lineal posibilitando de esta manera que se establezcan novedosas rutinas de trabajo en el seno de la entidad.

Hablamos de un experto en una comunicación en la que Postigo señala cómo:

Las nuevas tecnologías han de proporcionar alguna ventaja añadida al usuario de la misma, ya que de otro modo, el público no se vería en la necesidad de enfrentarse a estos nuevos instrumentos tecnológicos, no tendría motivación para aprender el manejo de los equipos informáticos, de las redes de comunicación, no vencería ese miedo a lo desconocido que a todos nos asalta cuando nos enfrentamos ante un nuevo instrumento. (Postigo, 2010, pp. 32-33).

Un comunicador capaz de crear no sólo mensajes adecuadamente estructurados al espacio cibernético en el que van a aparecer para que el usuario no se sienta perdido a la hora de leerlos, sino además, suficientemente atractivos como para que en éste no aparezca el deseo de acceder a otra página competidora. (Íbid).

Por otro lado, este nuevo profesional de la comunicación no ha de ser ajeno a la especial relación que se establece entre el emisor y el receptor en las Redes Sociales, donde la interacción que se da entre ambos ya no es lineal ni unidireccional, sino que ha virado a la multidireccionalidad; es decir, es el usuario el que elige su foco de atención según sus necesidades redireccionando la comunicación en función de lo que le interesa. En esta misma línea, Postigo remarca la alteración jerárquica que se produce en comparación con la comunicación tradicional, donde "el receptor ocupa el último lugar, y su capacidad de actuación es minima". Con Internet, sin embargo, "el receptor es activo y, además, busca en el medio precisamente esa libertad de acción". (Íbid, p. 35). 


\subsection{Otras destrezas a tener en cuenta}

Toda empresa o institución que desee afianzar su posicionamiento en el mercado proyectando al exterior una imagen suficientemente atractiva para los consumidores o usuarios, a tenor de los tiempos que corren, ha de poseer un profesional entre sus trabajadores dedicado exclusivamente a la tarea de inspección y actualización de su perfil en las diversas Redes Sociales online existentes.

Si bien nosotros abogamos desde aquí porque esta persona sea un profesional docto en cuestiones relacionadas fundamentalmente con el mundo de la comunicación algo para lo que apostamos sean las Facultades de Comunicación las que se encarguen de su formación específica- ha de saber conjugar al mismo tiempo saberes procedentes de otros ámbitos. Entre ellos, por ejemplo, hemos de reseñar las habilidades tecnológicas, esto es, del sinfín de herramientas con las que ha de contar para rentabilizar sus esfuerzos a la hora de lograr los objetivos marcados. Por otro lado, a nuestro juicio, un buen Community Manager ha de poseer, al mismo tiempo, habilidades propias del marketing y de la publicidad.

Acorde con esta última formación reseñada, es importante apuntar cómo el auge de Internet-Redes Sociales en los últimos lustros ha propiciado que el binomio anterior haya terminado convirtiéndose en el mejor de los soportes publicitarios conocidos hasta el momento. En este sentido, las nuevas vías online de comunicación permiten que las empresas apuesten cada vez más no por distribuir sus mensajes a través de la radio, prensa o televisión, sino por anunciarse online dirigiendo sus mensajes a segmentos de consumidores determinados e incluso, por qué no hacerlo, a usuarios de forman individual. El resultado final de este nuevo camino será, en palabras de Maqueira y Bruque, "una acción de marketing más concreta y específica, dirigida a un grupo social para el que la acción resulta de interés y que autodifundirá el mensaje entre los miembros de la Red". (Maqueira \& Brunque, 2009, p. 16).

Por otro lado, debe poseer un conocimiento profundo de la empresa para la que trabaja y la industria en la que ésta se ubica, sentido común, inteligencia contextual, empatía, honestidad, etc. En definitiva, un profesional seguro y responsable capaz de responder rápidamente a las necesidades de los usuarios, tomar decisiones sin tener que ser constantemente supervisado por sus jefes y, además, versátil, es decir, con capacidad suficiente como para saber responder a los cambios e incluso anticiparse a ellos.

\section{CONCLUSIONES}

¿Qué es, por lo tanto, un Community Manager? ¿En qué consiste esta nueva nrofeción nacida al ahrion del univerco ? M? Fnenntrar 11na definición a11e se ai11cte 
verdaderamente a lo que nosotros entendemos ha de considerarse un profesional más de los medios de comunicación (Internet es un mass media, no lo olvidemos) es tarea compleja.

Como nuevo perfil profesional unido a los medios de comunicación, su destreza fundamenta ha de ser, por lo tanto, la comunicación.

Una comunicación perfectamente estructurada y estratégicamente articulada con el fin último de alcanzar el que debe ser su principal objetivo: lograr una interacción fluida con los usuarios de los servicios que oferta la empresa para la que trabaja. Todo ello enmarcado en la vorágine de cambios protagonizada por las Redes Sociales, un fenómeno nacido hace apenas una década pero que gana adeptos de forma exponencial a lo largo y ancho del Planeta.

Si hemos definido la comunicación como herramienta imprescindible del día a día de todo Community Manager, resulta lógico pensar, por lo tanto, que las Facultades de Comunicación deberían convertirse en tutores únicos de estos nuevos profesionales. Es decir, sólo incluyendo esta especialización entre las materias ofertadas en sus planes de estudio sería posible que este nuevo perfil alcanzara todas las habilidades necesarias para lograr un posicionamiento firme en un mercado laboral creciente, como es el vinculado con las nuevas tecnologías y, de manera más específica, con el mundo 2.0 .

Todo, por supuesto, sin dejar al margen materias tan fundamentales como lo son la publicidad, los recursos humanos o la publicidad, que no vendrían sino a complementar y enriquecer a todos los individuos que formaran parte de este nicho profesional.

\section{REFERENCIAS}

Beelen, P. (2006). Publicidad 2.0. Recuperado el 20 de julio de 2011, de www.paulbeelen.com/whitepaper.

Castells, M. (2001). La era de la información. Economía, sociedad y cultura. Madrid: Alianza Editorial.

Castellls, M. (2006). La sociedad red: una visión global. Madrid: Alianza Editorial.

Castillo Esparcia, A. (2005). Comunicación organizacional. Teorías y Estudios. Málaga: Clave Aynadamar.

Celaya, J. (2008). La empresa en la Web 2.0: el impacto de las nuevas redes sociales en la estrategia empresarial. Barcelona: Turisverd,

Christakis. N. A. \& Fowler. I. H. (2010). Conectados. El sornrendente noder de las Redes 
Sociales y cómo nos afectan. Madrid: Taurus.

Cornwell, B. \& Lundgren, D.C. (2001). Love on the Internet: Involvement and Misrepresentation in Romantic Relationship in Cyberspace vs. Realspace. Computer in Human Behavior, 17.

De Salas Nestares, M. I. (2010). Estrategias empresariales en la Web 2.0. Las redes sociales online. Alicante: Club Universitario San Vicente.

Falla Aroche, S. (2010). ¿Qué es un Community Manager? Recuperado el 30 de julio de 2011, de http://www.maestrosdelweb.com/editorial/que-es-un-communitymanager/.

Fundación de la Innovación Bankinter. (2007). Web 2.0.: El negocio de las Redes Sociales. Madrid: Fundación de la Innovación Bankinter.

Hampton, K. N. (2006). La sociabilidad en red dentro y fuera de la Web. En La sociedad red: una visión global. Madrid: Alianza Editorial.

Hernández, P. (2011). Tendencias de Web 2.0 aplicadas a la educación en línea. No solo usabilidad. Revista multidisciplinar sobre diseño, personas y tecnología. Recuperado el 15 de julio de 2011, de http://www.nosolousabilidad.com/articulos/web20.htm. Consultado el.

Lenderman, M. \& Sánchez, R. (2008). Marketing Experiencial. La revolución de las marcas. Madrid: ESIC Editorial.

Maqueira, J. M. \& Bruque, S. (2009). Marketing 2.0. El nuevo marketing en la web de las redes sociales. Madrid: Rama.

Méndez, M. Á. \& Segovia, A. (2011). Sí hay burbuja: se llaman community manager. El País. Recuperado el 15 de mayo de 2011, de Web:http:/ / www.elpais.com/articulo/tecnologia/hay/burbuja/llama/community /manager/elpeputec/20110607elpeputec_3/Tes.

Navarro, S. (2004). Redes Sociales y construcción comunitaria. Madrid: Editorial CCS.

O'reilly, T. (2005). What is Web 2.0? Design Patterns and Bussiness Models for the Next Generation of Software. Recuperado el 20 de julio de 2011, de http:// www.oreillynet.com/pub/a/oreily/tim/news/2005/09/30/what-is-web20.html. 
En Comunicación Organizacional. Teorías y Estudios. Málaga: Clave Aynadamar.

Requena Santos, F. (2003). Análisis de Redes Sociales. Orígenes, teorías y aplicaciones. Madrid: Centro de Investigaciones Sociológicas.

Schmitt, B. (2000). Experiential Marketing. Bilbao: Deusto S.L.

Tapscott, D. \& William, D. (2007). Wikinomic. La nueva economía de las multitudes inteligentes. Barcelona: Paidós Ibérica Ediciones.

Villafañe, J. (1999). La gestión profesional de la imagen corporativa. Madrid: Ediciones Pirámide.

\section{Rocío Alcántara López}

Licenciada en Periodismo por la Universidad de Sevilla (2001-2005), en estos momentos es Doctoranda del Departamento de Periodismo II de la Facultad de Comunicación de la citada Universidad. Tras haber ejercido varios años como profesional de la información en diversos Medios de Comunicación, fundamentalmente prensa especializada, hoy está centrada en el ámbito académico, donde prepara la defensa de su Tesis Doctoral en la línea de investigación 'Estrategias de la Comunicación'. Además, ha participado en numerosos congresos como comunicante, posee varios capítulos en libros y ha formado parte de la Secretaria Ejecutiva de la Organización de varios Congresos y Jornadas. En estos momentos tiene reconocida la Suficiencia Investigadora por la Universidad de Sevilla. 